\title{
Crime Hediondo e Progressão de Regime (Uma Análise à Luz da Dogmática Constitucional Moderna)
}

\author{
Paulo Quezado
}





\section{Crime Hediondo e Progressão de Regime (Uma Análise à Luz da Dogmática Constitucional Moderna)}

\section{IIMPORTÂNCIA DO TEMA}

O Supremo Tribunal Federal encontra-se na iminência de pôr um ponto final ao debate em torno da aplicabilidade ou não da progressão de regime de pena aos condenados nos crimes hediondos (HC 82.959). A matéria, que até o momento parecia caminhar para a consagração da tese negativa ${ }^{1}$, no sentido da constitucionalidade do proibitivo do art. $2^{\circ}$ da Lei 8.072/90, exsurge agora, com toda força, por nova orientação, após a $1^{\mathrm{a}}$ Turma do STF haver concedido, em recentes decisões, (HCs 87.623 e 87.452), o benefício referido a condenado em delitos dessa natureza.

Tenho que, obrigatoriamente, uma séria discussão sobre a matéria não pode preterir da moderna concepção de Estado, da visão sistêmica do Direito, do que se entende por proteção do núcleo essencial da Constituição e da importância dos princípios na aplicabilidade das normas jurídicas. Qualquer outra orientação que ignore tais fundamentos, não há de legitimar-se como justa perante a ordem jurídica nacional.

\section{As Bases Jurídicas da TeSe Negativa}

Mas, antes de mais nada, necessário se faz expor as razões nas quais se fiam os defensores da não-aplicabilidade da progressão de regime nos casos de condenados em crimes hediondos. Em síntese, tem-se argumentado que o princípio constitucional da individualização das penas é de aplicabilidade restrita, voltado apenas ao legislador; que a progressividade na execução penal não se encontra entre as preocupações fundamentais do constituinte;

${ }^{1}$ Há inclusive a Súmula 698 do STF: "Não se estende aos demais crimes hediondos a admissibilidade de progressão no regime de execução da pena aplicada ao crime de tortura." 
que à Constituição não cabe disciplinar forma de cumprimento de pena, mas ao legislador ordinário foi-lhe concedida tal incumbência, pela própria Carta Política (art. $5^{\circ}$, XLVI) e que, por fim, o estabelecido na Lei dos Crimes de Tortura (Lei 9.455/97) deve ser visto apenas pelo prisma da especialidade legal. Tudo isso encontraremos exposto como base, com suas respectivas variáveis, em julgados e nos manuais de direito penal de todo país, para reafirmar a constitucionalidade do art. $2^{\circ}, \S 1^{\circ}$, da Lei 8.072/90 (Lei dos Crimes Hediondos).

\section{O Núcleo Fundamental dos Valores Constitucionais e o Princípio da Reserva Legal}

Como afirmamos linhas atrás, uma solução justa para o debate não pode deixar de percorrer os caminhos da moderna dogmática constitucional. E entre os trechos dessa jornada está imprescindivelmente o da visão sistêmica do direito. Na lição de Norberto Bobbio “... Direito não é norma, mas um conjunto coordenado de normas, sendo evidente que uma norma jurídica não se encontra jamais só, mas está ligada a outras normas com as quais forma um sistema normativo." 2 Se aqui estivesse o jurista italiano, com certeza, diria aos intérpretes da Lei 8.072/90, que primeiramente canalizassem todas suas energias intelectivas a elucidar os vetores constitucionais orientadores da formação desta lei, entendendo a parte através do todo fundamental.

Nesse passo, é que fazemos nosso o ensino do célebre jurista Hermes Lima:

"Não formula o Estado a lei que entende, senão a lei compatível com as condições sociais dominantes"'3. Poderíamos dizer, por outras, que o Estado não é livre para elaborar leis ao seu bel prazer, mas somente leis afinadas com a ideologia ${ }^{4}$ inspiradora do sistema constitucional moderno. E essa ideologia, sobre a qual deve assentar-se obrigatoriamente todo a produção normativa do Estado, vê-se positivamente delineada no art. $1^{\circ}$ da Constituição Federal, ao prescrever esta que a "República Federativa do

\footnotetext{
Teoria do ordenamento jurídico. $4^{\mathrm{a}}$ ed. Brasília: EDUNB, 1994, p. 21.

Introdução à Ciência do Direito. RJ: Livraria Freitas Bastos, 1989, p. 114.

Ideologia no sentido de conjunto de idéias próprias de uma sociedade em determinada época, que se orientadas para legitimar a ordem estabelecida.
} 
Brasil (...) constitui-se em Estado Democrático de Direito e tem como fundamentos: I - a soberania; II - a cidadania; III - a dignidade da pessoa humana; IV - os valores sociais do trabalho e da livre iniciativa; $\mathrm{V}$-o pluralismo político. E que "todo o poder emana do povo, que o exerce por meio de representante eleitos ou diretamente, nos termos desta Constituição."

Portanto, há um núcleo fundamental na Constituição, do qual nem o legislador, nem o intérprete podem dele afastar-se. No magistério autorizado do Min. Gilmar Mendes, conquanto "o texto constitucional brasileiro não tenha estabelecido expressamente a idéia de um núcleo essencial, é certo que tal princípio decorre do próprio modelo garantístico utilizado pelo constituinte". E arremata enfaticamente o jurista: "A não-admissão de um limite ao afazer legislativo tornaria inócua qualquer proteção fundamental."

Enfim, nossa Constituição consagrou, após todo o movimento constitucionalista até hoje, um Estado delimitado pelo Direito e em prol prioritariamente do homem, por isso também democrático, obliterando em definitivo a idéia de um Estado que tudo pode. Eé salutar trazermos à memória esse fundamento da teoria do Estado, porque põe abaixo, sob base eminente constitucional, o argumento daqueles que entendem, para legitimar a não-progressão de regime nos crimes hediondos, que o constituinte originário deu carta branca ao legislador ordinário na regulamentação do princípio da individualização das penas, através do princípio da reserva legal (art. $5^{\circ}$, XLIII e XLVI). O que é de uma ilogicidade jurídica desmedida, que se nos antefigura uma total ignorância dos valores orientadores do sistema constitucional; e como sempre dizia o mestre Ataliba, pior do que ferir a Constituição é ignorá-la, ou na sábia expressão do jurista Celso de Mello, ao criticar o desprezo à autoridade da Lei Maior, isto evidencia a erosão da consciência constitucional.

Bom é frisar que o princípio da reserva legal, como o próprio nome já o elucida, ergue-se sobre o núcleo fundamental da Constituição, tomando deste a força de sua existência. E como escreveu Bitencourt, o "princípio da reserva legal é um imperativo que não admite desvios nem exceções e representa uma conquista da consciência jurídica que obedece a exigência de justiça, que somente os regimes totalitários o têm negado". ${ }^{6}$

\footnotetext{
${ }^{5}$ HC 85.692/RJ. Vale a pena ler o inteiro teor do Voto-Vista do Min. GILMAR MENDES neste habeas corpus, onde expõe com a cientificidade que lhe é peculiar seu ponto de vista constitucional sobre o cabimento da progressão aos condenados em crimes hediondos. Seu voto aqui põe-se como um autorizado opúsculo em derredor do princípio da proteção do núcleo essencial, com incursão pela mais abalizada doutrina estrangeira.

Tratado de direito penal: parte geral. Vol. 1. SP: Saraiva, 2003, p. 10.
} 


\section{Z1 A Dignidade da Pessoa Humana e os Princípios Decorrentes}

Retomando o que falamos sobre os fundamentos do Estado Democrático de Direito, tem-se como essência deste Estado o resguardo ao princípio da dignidade da pessoa humana. Este princípio é de suma importância para o assunto em análise, pois nele radicam-se os demais vetores do direito penal, como: legalidade, adequação social, proporcionalidade, humanidade, necessidade etc, só para citar alguns. Na ênfase conclusiva de Capez: "Do Estado Democrático de Direito parte um gigantesco tentáculo, a regular todo o sistema penal, que é o princípio da dignidade humana, de modo que toda incriminação contrária ao mesmo é substancialmente inconstitucional". (Grifamos.) E esse princípio, como defende o autor, vincula não somente o trabalho do legislador, mas também do aplicador da interpretação da norma jurídica.

Irradiando-se desse princípio, tem-se também os princípios da humanidade, da culpabilidade e da individualização da pena, só para citar os que lançam diretamente luzes sobre a matéria. O princípio da humanidade veda todas as formas cruéis de pena e de seu cumprimento. Seria como diz Zaffaroni: "Do princípio da humanidade deduz-se a proscrição das penas cruéis e de qualquer pena que desconsidere o homem como pessoa". E é trilhando por essa orientação que Zaffaroni defende a aplicação absoluta do princípio não só em abstrato - pelo legislador-mas também em concreto, pelo juiz no momento de quantificar a pena. ${ }^{7}$ Outro que se põe em resguardo da dignidade da pessoa humana, é o princípio da culpabilidade, cujos sentidos dão os fundamentos da pena, os limites desta e afastam qualquer responsabilidade objetiva. ${ }^{8}$ E por fim, o princípio da individualização da pena que, apesar de destacado de forma expressa e distante dos princípios fundamentais $\left(\operatorname{art} .1^{\circ}\right.$ ), não deixa de radicar-se também na dignidade da pessoa humana.

Toda essa ênfase principiológica vem reafirmar a pujança dos vetores fundamentais previsto pela Constituição, que dão vida a qualquer outra regra constitucional ou legal do sistema. E nunca se pode olvidar a lição de há muito do mestre argentino, Agustín Gordillo, hoje já notória, de que violar um princípio é mais grave que transgredir uma norma, pois se assim ocorrer, todo o sistema estará comprometido.

Postas tais premissas, passamos agora ao segundo estágio do processo hermenêutico - o confronto da lei com os princípios e normas constitucionais.

\footnotetext{
7 Manual de direito penal brasileiro: parte geral. 5a ed. SP: RT, 2004, p. 172.

BITENCOURT, Cezar Roberto. Ob. cit., 14.
} 


\section{F) $O$ ART. $2^{\circ}, \S 1^{\circ}$, DA LEI 8.072/90 FRENTE À CONSTITUiÇão}

A Lei dos Crimes Hediondos, desde seu nascedouro, tem gerado diversas polêmicas. Entre as quais, a questão de ser aplicável ou não o instituto da progressividade aos condenados em crimes hediondos. Só a título de esclarecimento, a progressão no cumprimento da pena significa a transição do condenado de regime penal mais gravoso a uma forma mais branda, havendo preenchido certos pressupostos (art. 112 da LEP). Isso porque, como escreve Capez, a sentença penal condenatória surge no mundo jurídico sob a cláusula rebus sic stanbus, o que informa o caráter dinâmico da execução penal. Esse instituto, no entanto, foi proibido por lei quando tratarse de condenação em crime hediondo.

Antes de ir à letra da Lei 8.072, vejamos o que diz a CF sobre os crimes hediondos. $\mathrm{O}$ art. $5^{\circ}$, XLIII, assim dispôs:

"a lei considerará crimes inafiançáveis
e imprescritíveis de graça ou anistia a
prática da tortura, o tráfico ilícito de
entorpecentes e drogas afins, o
terrorismo e os definidos como crimes
hediondos, por eles respondendo os
mandantes, os executores e os que,
podendo evitá-los, se omitirem;"
- grifamos-

Ao definir tais crimes, a Lei 8.072/90 foi além, entre outros pontos de constitucionalidade discutível, e prescreveu:

"Art. $2^{\circ}$ Os crimes hediondos, a prática da tortura, o tráfico ilícito de entorpecentes e drogas afins e o terrorismo são insuscetíveis de:

$\S 1^{\circ}$ A pena por crime previsto neste artigo será cumprida integralmente em regime fechado". - grifamos- 
Como se vê, claramente, sem grande esforço hermenêutico, o legislador ordinário foi além do que permitiu a Constituição Federal. A Carta Política apenas impediu a aplicação da fiança, da graça e da anistia aos crimes definidos por lei como hediondos. O legislador não poderia exacerbar seu campo de atuação e tornar mais rígido o regime de cumprimento de pena de tais crimes, vedando ao condenado o benefício da progressão. A constitucionalidade aqui foi flagrante.

O que fez o legislador ordinário ao determinar que o condenado a tais crimes deveria cumprir pena inteiramente em regime fechado foi não só uma violação ao princípio da reserva legal, mas grave transgressão ao sistema constitucional vigente, verdadeiro bombardeio aos alicerces do Estado Democrático de Direito, na medida que ignorou a orientação dos princípios da dignidade da pessoa humana, da humanidade e da individualização da pena. Até mesmo por uma simples aplicação do bom senso, concluirá o homem médio que de forma alguma proibir alguém de gozar do benefício da progressão " instituto histórico do direito penal e de cunho eminente recuperatório do caráter humano " com provas incontestes de bom comportamento e tempo de pena cumprido, será uma demonstração do resguardo da dignidade humana.

Na verdade, tal forma de cumprimento de pena será o reverso da dignidade humana, qual seja: a crueldade na execução da pena, o que veda peremptoriamente a Constituição Federal (art. $5^{\circ}$, XLVII). Cernichiaro, que vê na vedação constitucional à pena cruel regra de cunho meramente declaratória do princípio da dignidade humana, esclarece que crueldade aqui "traduz a idéia de o agente infligir à vítima desnecessário padecimento físico ou moral, na execução do delito". Caricaturesco o exemplo do autor para demonstrar aqui a violação à dignidade humana. Suas palavras: "A chamada 'morte lenta' serve de ilustração. O cortar as mãos, arrancar lentamente as unhas, queimar os olhos com ferro em brasa provocam sofrimentos desnecessários para matar. De outro lado, submeter a vítima a constrangimentos morais conduz à mesma situação. No caso, ofender desnecessariamente o físico ou a dignidade da vítima atraem maior reprovabilidade." 9

\footnotetext{
${ }^{9}$ Direito penal na Constituição. SP: RT, 1990, p. 123.
} 
E é justamente contra tamanha crueldade na execução penal, que vale a pena insistirmos na lição de Zaffaroni: "Do princípio da humanidade deduzse a proscrição das penas cruéis e de qualquer pena que desconsidere o homem como pessoa". Justamente em proteção do princípio da humanidade que o STJ tomou, em 2005, a seguinte decisão:

"EMENTA: PENAL E PROCESSO PENAL. HABEAS CORPUS. CRIME HEDIONDO. REGIME INTEGRALMENTE FECHADO. I M P O S S I B I L I D A D E. PROGRESSÃO DE PENA. CONSTITUCIONALIDADE. A Constituição da República recepcionou o sistema progressivo de cumprimento de pena, constante do Código Penal e da Lei de Execução Penal. Negá-lo ao condenado por crime hediondo gera descabida afronta aos princípios da humanidade das penas e da sua individualização. Ordem CONCEDIDA para afastar a vedação legal à progressão de regime." (HC $44.504-\mathrm{DF}$ )

\section{(i) O PRINCÍPIO DA INDIVIDUALIZAÇÃO DA PENA}

Fundamento sobre o qual vem se sustentando parte do STF para negar a progressão de regime nos casos de crime hediondo encontra-se na análise sobre o princípio da individualização da pena, previsto no art. $5^{\circ}$, XLVI, da $\mathrm{CF}$, com os seguintes dizeres: "a lei regulará a individualização da pena (...)" Tem defendido o Pretório Excelso que tal princípio foi direcionado com exclusividade ao legislador que, pela letra do art. $5^{\circ}$, XLVI, da CF, goza de inteira discricionariedade em decidir qual o regime penal a ser cumprido pelos condenados em crimes dessa natureza. Indo mais além, diz que a progressividade não foi erigida a postulado constitucional e que o juiz, ao aplicar a pena devida, cumpriu com a individualização da pena, não operando daqui em diante tal princípio. 
Evidentemente, que essa visão amesquinha o alcance do princípio da individualização da pena, que, antes de mais nada, é um consectário normativo da proteção á dignidade humana. Sob uma ótica magistral e firme do que expomos sobre a dignidade humana, expõe com profundidade o Min. Cezar Peluso sua opinião sobre a abrangência constitucional do princípio em todas suas ramificações de aplicabilidade:

"É, pois, constitucional que a pena deve ser individualizada, ainda que nos limites da lei, e que sua execução em estabelecimento prisional deve ser individualizada, quando menos, de acordo com a natureza do delito, a idade e o sexo do apenado.

Evidente, assim, perante a Constituição, o princípio da individualização da pena compreende: a) a proporcionalidade entre o crime praticado e a sanção abstratamente cominada no preceito secundário da norma penal; b) individualização da pena aplicada em conformidade com o ato singular praticado por agente em concreto (dosimetria da pena); c) individualização da sua execução, segundo a dignidade humana (art. $1^{\circ}$, III), o comportamento do condenado no cumprimento da pena (no cárcere ou fora dele, no caso das demais penas que não a privativa de liberdade) e à vista do delito cometido (art. $5^{\circ}$, XLVIII).

Logo, tendo predicamento constitucional o princípio da individualização da pena (em abstrato, em concreto e em sua execução), exceção somente poderia ser aberta por norma de igual hierarquia nomológica. 
'A imposição de um regime único e inflexível para o cumprimento da pena privativa de liberdade', nota MARIA LÚCIA KARAM, 'com a vedação da progressividade em sua execução, atinge o próprio núcleo do princípio individualizador, assim, indevidamente retirando-lhe eficácia, assim indevidamente diminuindo a razão de ser da norma constitucional que, assentada no inciso XLVI do art. $5^{\circ}$ da Carta de 1988, o preconiza e garante'.

Já sob este aspecto falta, pois, legitimidade à norma inserta no $\S 1^{\circ}$ do art. $2^{\circ}$ da Lei n ${ }^{\circ} 8.072 / 90$." (HC 85.692-6/RJ)

Não procede também o argumento segundo o qual ao aplicar a pena estaria observado o princípio da individualização. Todo princípio traz ínsito em sua essência uma aplicabilidade dinâmica, pois ele exerce, antes de qualquer outra, uma função diretiva, indicando o caminho da proteção aos valores constitucionais vigentes. Nas sábias palavras do Min. Sepúlveda Pertence, “(...) esvazia e torna ilusório o imperativo constitucional da individualização da pena a interpretação que lhe reduza o alcance ao momento da aplicação judicial da pena, e o pretende, de todo impertinente ao da execução dela.

De nada vale individualizar a pena no momento da aplicação, se a execução, em razão da natureza do crime, fará que penas idênticas, segundo os critérios da individualização, signifiquem coisas absolutamente diversas quanto à sua efetiva execução.” (RTJ 147/608; HC 85.692/RJ) 
Como ensina o Min. Cezar Peluzo, o princípio da individualização da pena deve ser observado sob seu tríplice sentido: abstrato, concreto e em sua execução. Do contrário, será inverter a lógica do sistema, dando ao legislador ordinário poderes supraconstitucionais. Sendo assim, não se poderá aceitar que tal princípio foi dirigido exclusivamente ao Congresso Nacional, mas também ao aplicador da lei. Neste ponto, vale a pena transcrevermos parte do voto-vista do Min. Gilmar Mendes no HC 85.692:

"O entendimento segundo o qual a disposição constitucional sobre a individualização estaria exclusivamente voltada para o legislador, sem qualquer significado para a posição individual, além de revelar que se cuidaria então de norma extravagante no catálogo dos direitos fundamentais, esvaziaria por completo qualquer eficácia dessa norma. É que, para fixar a individualização da pena in abstracto, o legislador não precisaria sequer de autorização constitucional expressa. Bastaria aqui o critério geral do nullum crimen, nulla poena sine lege.

Em verdade, estou convencido de que fórmula aberta parece indicar, tal como em relação aos demais comandos constitucionais que remetem a uma intervenção legislativa, que o princípio da individualização da pena fundamenta um direito subjetivo, que se não se restringe à simples fixação da pena in abstracto, mas que se revela abrangente da própria forma de individualização (progressão).

Em outros termos, a fórmula utilizada pelo constituinte assegura um direito 
fundamental à individualização da pena. A referência à lei-princípio da reserva legal - explicita tão-somente, que esse direito está submetido a uma restrição legal expressa e que o legislador poderá fazer as distinções e qualificações, tendo em vista as múltiplas peculiaridades que dimanam da situação a reclamar regulação.

É evidente, porém, como todos sabem, que a reserva legal também está submetida a limites. Do contrário, terse-ia a possibilidade de nulificação do direito fundamental submetido à reserva legal por simples decisão legislativa. Este é o cerne da questão. Se se está diante de um direito fundamental à individualização da pena e não de uma mera orientação geral ao legislador - até porque para isso despicienda seria a inclusão do dispositivo no elenco dos direitos fundamentais - então há que se cogitar do limite à ação do legislador na espécie." - grifamos -

\section{G A Lei da Tortura e o Bloco de Constitucionalidade}

Além de todas as razões até aqui expostas, pelas quais temos pela inconstitucionalidade da negativa legal de progressão nos crimes hediondos, o disposto no art. $1^{\circ}, \S 7^{\circ}$, da Lei 9.455/97 (Lei da Tortura) vem reforçar nosso posicionamento. Não se pode aceitar que o condenado a um crime tão infame como a tortura, de crueldade ímpar, tenha direito à progressão, e outros da mesma forma não o tenham apenas porque foram condenados a crimes tidos como hediondo.

Aliás, a tortura foi alvo de igual intensidade das preocupações do legislador constituinte, quando proibiu a fiança, a graça e a anistia em tais crimes, 
assim como nos hediondos. No mínimo caberia aqui a aplicação da analogia in bona parte aos condenados em crimes hediondos. O mero bom senso já diz que a tortura é tão hedionda quanto os demais crimes hediondos.

Ademais, o legislador ao formular leis deve ter em vista, obrigatoriamente, o sistema, de forma a não afetar o chamado bloco de constitucionalidade, tema da dogmática constitucional moderna. Isso significa que a Constituição não se restringe a um conjunto de normas e princípios explícitos e implícitos, mas vai além, alcançando as normas de caráter infraconstitucional com aptidão a desenvolver a eficácia dos postulados eminentemente constitucionais. Seria observância da unidade axiológica do ordenamento jurídico nacional.

Enfim, este é o nosso parecer. E enquanto aguardamos o pronunciamento em definitivo sobre a matéria, fazemos nossas as célebres palavras do grande Rui Barbosa: "Aqui (no STF) não podem entrar as paixões, que tumultuam a alma humana, porque este lugar é refúgio da Justiça. A Justiça é a minha ambição, senhores juízes; a Justiça para qual se voltam os interesses contemporâneos, mas que deve cobrir igualmente as gerações futuras, ou entregá-las indefesas às intempéries da força, se lhe faltar de vossa parte a proteção de um arresto reparador."10 (Acréscimo nosso.)

\footnotetext{
${ }^{10}$ Obras seletas. Vol. IX. FCRB: São Paulo, 1958, p.16.
} 